\title{
Analysing Deposition and Site Formation Processes in Medieval Cess Pits Using Bone Fragmentation
}

\author{
Emily V. Johnson, Hayley Forsyth-Magee and lan Hogg
}

Signatures of animal bone fragmentation have huge potential for understanding deposition and archaeological site formation processes, yet they are scarcely studied, especially in medieval urban contexts. Archaeological investigations at 1-5 Benjamin Street, Farringdon uncovered a number of medieval cess pits and other contexts associated with the Hospitaller Priory of St John of Jerusalem. The well-preserved zooarchaeological assemblage from these contexts was deemed an excellent case study for in-depth bone fragmentation analysis to both test and display the utility of the method at this type of site.

The analysis revealed that material from the lowest fills of the cess pits differed from the upper fills in that fragmentation was more intensive. Based on the size and weight of fragments, and surface modifications related to burning and taphonomy, we postulate that floor and hearth sweepings were occasionally deposited in the cess pits whilst they were in use. This material was likely further fragmented when cess pits were periodically emptied. Faunal specimens in the upper fills have different fragmentation and taphonomic signatures and more likely relate to opportunistic refuse deposition or capping after the use of the cess pits. This analysis shows the archaeological potential of this approach when aligned with specific research questions concerning deposition.

\section{Introduction}

Between 2015 and 2017 Archaeology South-East (UCL Institute of Archaeology) conducted a series of archaeological investigations at 1-5 Benjamin Street, Farringdon. The site was located in the south-western corner of the outer precinct of the Hospitaller Priory of St John of Jerusalem. The work found evidence of medieval cess

Archaeology South-East, Institute of Archaeology, UCL Portslade, Brighton, East Sussex, GB

Corresponding author: Emily V. Johnson (emily.johnson@ucl.ac.uk) pits associated with the priory; these large, deep and generally rectangular pits were laid out in a systematic manner, on the same alignment and frequently very close to one another. The 12 pits generally contained organic, cess-rich lower fills, leading to their determination as cess pits, with upper capping fills of clay and tile. The main phase of pitting was dated to the $13^{\text {th }}-14^{\text {th }}$ centuries, with a secondary phase of cess pit activity in the late medieval period before the break-up of the Priory during the dissolution.

Bone fracture freshness and fragmentation analysis has huge potential to contribute 
to an understanding of food preparation and consumption, deposition practices, and site formation (Johnson 1985; Johnson, Parmenter and Outram 2016; Outram 2001). Despite this, the use of this technique is rare, particularly for medieval urban assemblages. The cess pits from Benjamin Street make a particularly interesting application for this type of analysis based on the cess and noncess material often found in these contexts (Smith 2013), and the disturbance caused through periodic emptying (Evans 2010). The zooarchaeological material itself $(n=2647$, $1954.6 \mathrm{~g}$ ) is also well-suited given the retention of small bone fragments through bulk sampling and excellent preservation. The research aim was to test the utility of bone fracture freshness and fragmentation analysis on a medieval cess pit assemblage to better understand the deposition processes contributing to the formation of the cess pit fills.

\section{Methodology}

Where possible, bones were identified to species, element and bone zone (Serjeantson 1996); taxa size (large/ medium/ small) and type (mammal/ bird/ fish) were recorded for partially identifiable material. Evidence of butchery, burning, gnawing and taphonomic agents was recorded by type and bone zone affected. Crucially, indeterminate material was included in this analysis as it contains important information about the assemblage despite not being identifiable to taxon (Outram 2001).

Analysis of fragmentation, which assesses how broken up the whole assemblage is, involved recording bone weight and a size class based on maximum dimensions (Outram 2001). All bones were weighed to within $0.01 \mathrm{~g}$. Size classes were in $10 \mathrm{~mm}$ increments up to $60 \mathrm{~mm}$, then $60-79 \mathrm{~mm}, 80-99 \mathrm{~mm}$, and $100 \mathrm{~mm}$ or over. Correspondence analysis was used to visualise the differences in population frequencies between contexts using PAST3 software (Hammer, Harper and Ryan 2001).

Fracture freshness analysis has the potential to explain patterns of fragmentation, as bones break in different ways depending on how much moisture has been lost during degradation (Johnson 1985; Outram 2001). For example, fractures caused when splitting long bones from a recently killed animal to access marrow look very different from those on bones broken during the disturbance of an old midden context. Fresh (peri-mortem) bone breaks with a helical (curving) fracture outline, a smooth fracture surface, and acute angles of the internal and external cortical surfaces to the fracture surface. Fresh fracture is usually indicative of marrow extraction. As bone dries out, fracture outlines become jagged or straight, the fracture surface is rough or grainy and the angle of the fracture surface to the cortical surface becomes closer to a right angle. These 'dry' fracture characteristics are most pronounced in mineralised bone, which has lost all moisture content and thus presents fractures with flat, straight outlines, $90^{\circ}$ angles and grainy surface textures. Dry and mineralised fracture often occurs as a result of taphonomic disturbance, such as trampling, redeposition, or recutting of contexts. Recent breaks, caused during and after excavation, look different again, being white and chalky. The presence of any of these four fracture types (fresh, dry, mineralised and new) was recorded on marrow-bearing bone (the humerus, femur, radius, tibia, mandible and metapodia), and partially identifiable long bone fragments.

\section{Results}

The focus of this analysis is on the fills of suspected cess pits dating to the $13^{\text {th }}-14^{\text {th }}$ centuries, with two non-cess pit contexts (quarry pit [1003] and refuse pit [1077]) also compared from this period. Two fills of a further cess pit [1072] were dated to the $17^{\text {th }}$ century (Table 1). Contexts are discussed as fills of their parent, to make associations clearer.

A full analysis of zooarchaeological data was undertaken for a post-excavation assessment (ASE 2019; see also Hogg et al. in prep.). Briefly summarised, faunal remains 
Table 1: Zooarchaeological assemblage from 1-5 Benjamin Street by context. Contexts are arranged by period, and grouped within those periods based on their parent context. The [Cut] is used in graphical representation.

\begin{tabular}{|c|c|c|c|c|c|}
\hline [Cut] Fill & Context & Bulk sample & Description & $\mathbf{N}$ & Weight (g) \\
\hline [1003] 1 & 1045 & 14 & $\begin{array}{l}\text { Primary fill of quarry pit [1003], likely } \\
\text { used for deposition of cess }\end{array}$ & 60 & 4.5 \\
\hline [1077] 1 & 1080 & 20 & Primary fill of refuse pit [1077] & 460 & 47.36 \\
\hline [1005] 1 & 1026 & 10 & Primary fill of cess pit [1005] & 66 & 23.2 \\
\hline [1005] UP & 1004 & & Upper fill of cess pit [1005] & 1 & 10.2 \\
\hline [1014] 1 & 1013 & & Primary fill of cess pit [1014] & 7 & 41.4 \\
\hline$[1014] 2$ & 1012 & & Secondary fill of cess pit [1014] & 2 & 11.3 \\
\hline [1014] UP & 1011 & & Upper fill of cess pit [1014] & 28 & 264.6 \\
\hline [1020] 2 & 1019 & 11 & Secondary fill of cess pit [1020] & 167 & 94.8 \\
\hline [1024] 1 & 1023 & 13 & Lowest fill of cess pit [1024] & 170 & 55 \\
\hline$[1024] 2$ & 1043 & 15 & Secondary fill of cess pit [1024] & 542 & 475.7 \\
\hline [1033] 1 & 1032 & 12 & Primary fill of cess pit [1033] & 11 & 4 \\
\hline [1033] 2 & 1031 & & Secondary fill of cess pit [1033] & 1 & 14.2 \\
\hline [1037] 1 & 1046 & 16 & Primary fill of cess pit [1037] & 111 & 16.9 \\
\hline [1047] 1 & 1050 & 18 & Primary fill of cess pit [1047] & 129 & 8.7 \\
\hline$[1055] 2$ & 1053 & 17 & Secondary fill of cess pit [1055] & 195 & 474 \\
\hline [1065] 3 & 1062 & & Tertiary fill of cess pit [1065] & 1 & 67.1 \\
\hline$[4 / 008] 2$ & $4 / 006$ & & Secondary fill of cess pit [4/008] & 1 & 42.9 \\
\hline [4/010] S & $4 / 009$ & & Single fill of cess pit $[4 / 010]$ & 5 & 115.5 \\
\hline [1072] 1 & 1076 & 19 & Primary fill of cess pit [1072] & 689 & 182.1 \\
\hline [1072] UP & $5 / 008$ & & $\begin{array}{l}\text { Upper fill of cess pit [1072], from } \\
\text { evaluation slot }\end{array}$ & 1 & 2.91 \\
\hline
\end{tabular}

present include domestic cattle, ovicaprids, and pigs, as well as dogs and cats, birds such as chicken, duck and goose and large quantities of wild taxa consisting of small mammals; rabbit, rat, mouse/vole and especially fish. Some elements were whole, including a dog skull from the secondary fill of cess pit [1024], ovicaprid cranial and post-cranial elements from the single fill of cess pit [4/010] and the upper fill of cess pit [1014] respectively, and also including small mammal and avian bones. However, the assemblage was dominated by highly fragmented bone for which taxon could not be determined.

\section{Fragmentation}

Analysis of this bone fragmentation yielded interesting results aiding interpretations of the depositional sequence of the cess pits. It suggested that the primary fills of the cess pits, refuse pit [1077] and quarry pit [1003] were subjected to a higher degree of fragmentation than later fills. Figure $\mathbf{1}$ displays this variance in fragmentation using correspondence analysis (CA) to visualise the distribution of weight in different size classes for each fill. The CA shows that many primary fill contexts associate with size classes $<40 \mathrm{~mm}$ in maximum dimensions, indicating 


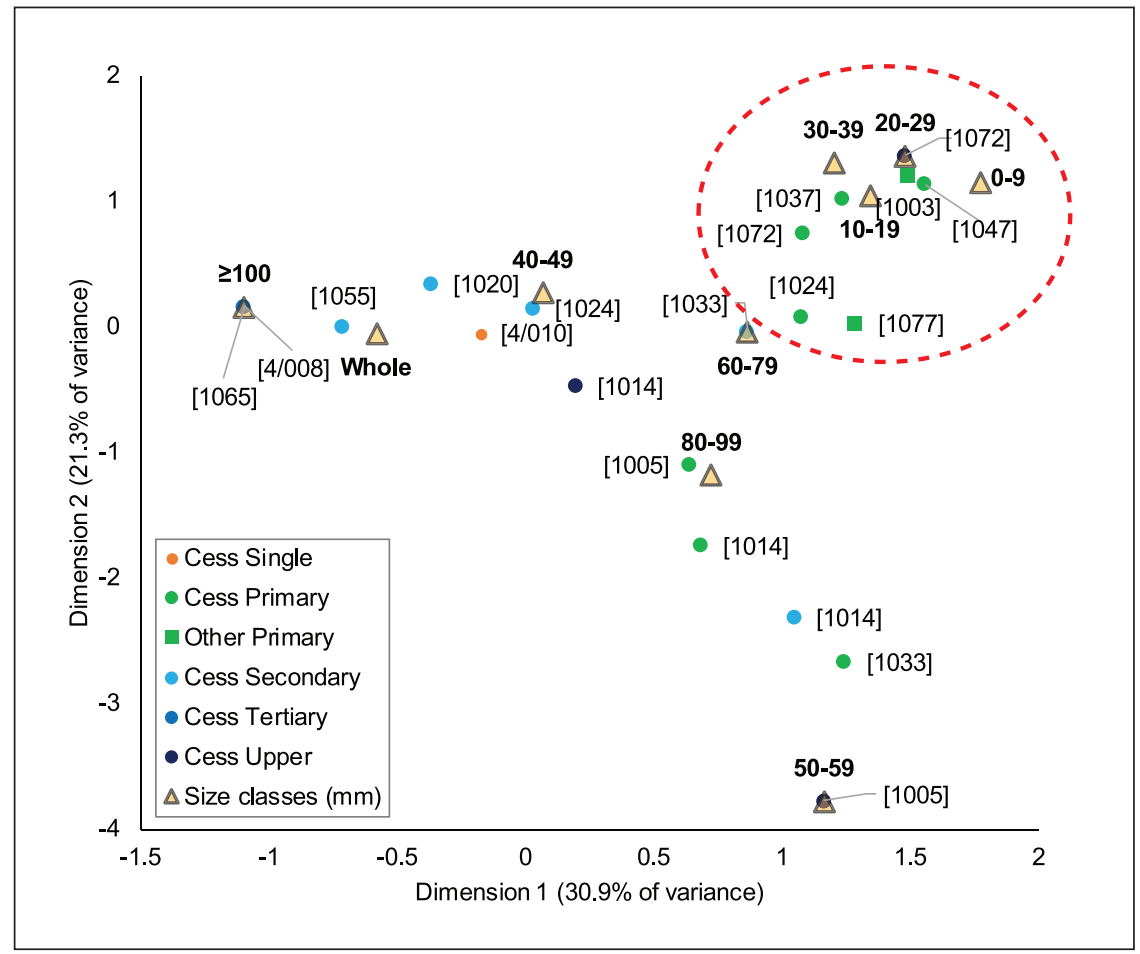

Figure 1: Correspondence analysis of the weight proportion in each size class ( $\mathrm{mm})$, with whole bones categorised separately. Figure: E. V. Johnson

that the majority of the assemblage weight was comprised of bones of this size (circled in Figure 1). Later fills tended to be less fragmented, having much larger bone fragments or whole bones. Although fragmentation was better represented in bulk-sampled fills due to increased retention of small bone fragments, bulk-sampled secondary fills were still generally less fragmented (for example, the secondary fills of [1020] and [1055]) than their bulk-sampled primary counterparts. The lower and secondary fills of cess pit [1024] were particularly good examples of this trend, with the primary fill [1023] $<13>$ having $40.3 \%$ of its assemblage weight in the $<30 \mathrm{~mm}$ size classes $(\mathrm{n}=55.03 \mathrm{~g}$ ), whereas secondary fill [1043] $<15>$ had just $12.4 \%(\mathrm{n}=475.7 \mathrm{~g})$, a significant difference $\left(\chi^{2}=27.596\right.$, d.f. $\left.=1, p<0.001\right)$.

\section{Fracture freshness}

The excellent condition of the assemblage and rarity of recent breaks $(n=6)$ indicates that fragmentation was not a result of poor preservation. Fracture freshness analysis has the potential to explain the processes contributing to this fragmentation, yet suitable bones were scarce ( $n=58$ across all contexts) and cannot be compared contextually. The presence of fresh (peri-mortem) fracture affecting $32.8 \%$ of fractured bones suggests some exploitation of bone marrow, but taphonomic fracture was the dominant fracture type, with dry fracture affecting $63.8 \%$ of fractured specimens and mineralised fracture $3.4 \%$. This suggests disturbance and breakage after the bone had lost moisture - either before deposition in the pits, when pits were emptied, or if material from the upper fills was redeposited from temporary dumps.

\section{Taphonomy}

Analysis of bone surface modifications revealed that contexts with high fragmentation also had high frequencies of burnt bone, almost entirely carbonised and calcined (i.e. burnt at high temperatures). There was a 


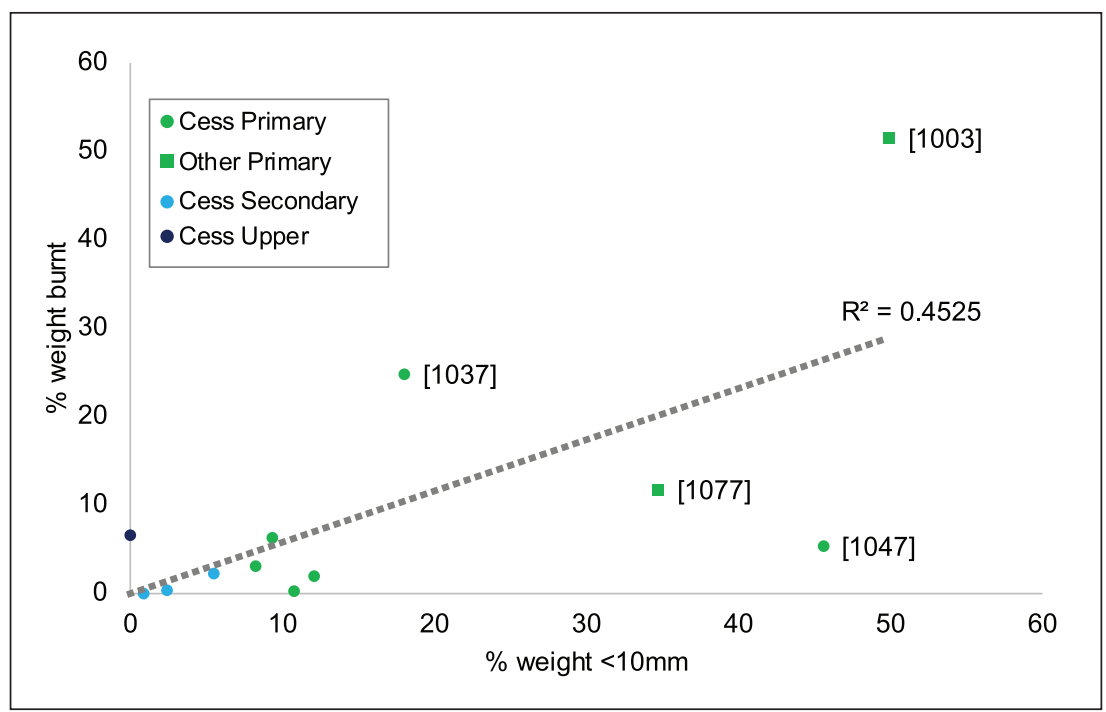

Figure 2: Proportion of bones showing evidence of heat exposure (by weight) against the proportion of the assemblage weight $<10 \mathrm{~mm}$ in maximum dimensions in each context. Figure: E. V. Johnson

positive correlation between the weight of bone $<10 \mathrm{~mm}$ in maximum dimensions and the weight proportion of all bones burnt $\left(R^{2}=0.45\right.$; Figure 2$)$ in contexts with over 10 specimens (see Table 1). Highly fragmented bone burnt at high temperatures could suggest that fills were partially comprised of hearth sweepings, particularly in the two non-cess pit contexts [1077] and [1003].

Although there was no direct evidence of digestion, evidence of mastication was present. Gnawing activity by domestic dogs $(\mathrm{n}=21)$ and rodents $(\mathrm{n}=3)$ was identified on bones from cess pits and associated contexts, including both primary and upper fills. This suggests that scavengers had access to refuse, and may have contributed to fragmentation levels. Fish bones with crushing may be indicative of human digestion where the bones are very small, but those over $1 \mathrm{~cm}$ in maximum dimensions more likely represent accidental mastication and subsequent expectoration by humans, possibly further evidence of floor sweepings.

\section{Conclusion}

Analysing the signatures of bone fragmentation in the assemblage at Benjamin Street has enabled a better understanding of the nature of the deposition practices associated with the Hospitaller Priory of St John of Jerusalem and its surrounds. The animal bone from the primary fills of cess, refuse and quarry pits is suggestive of floor and hearth sweepings, although it is likely that a mixture of material is represented, including cess. Already fragmented by burning and other taphonomic processes such as trampling, further fragmentation may have occurred during periodic emptying, as has been postulated from similar medieval cess pit assemblages (Greig 1981: 275; Rielly 2006; Smith 2013). Larger bones and other archaeological material including CBM and pottery in upper fills may represent refuse opportunistically dumped once cess pits fell out of use, or intentional capping. These upper fills are likely to have derived from the tile making industry which was active in the area (Betts 2002: 10) and suggests that a relationship may have existed between this industry and the priory (ASE 2019; Hogg et al. in prep.).

This analysis is particularly significant in that it reveals the wealth of information that can be gained from a largely indeterminate 
zooarchaeological assemblage, which could be key to understanding depositional histories on archaeological sites with similar faunal material.

\section{Acknowledgements}

The authors would like to thank all archaeologists who worked on the excavation, and those who were involved in the environmental processing of bulk samples. The Benjamin Street excavation was directed for Archaeology South-East by Ian Hogg with Sarah Ritchie, Steve White and Tomasz Mazurkiewicz. The work was commissioned by CgMs Consulting on behalf of their client Knight Harwood and is the subject of a forthcoming article 'Excavations at 1-5 Benjamin Street, Farringdon; activity and tile making at the Hospitaller Priory of St John of Jerusalem' to be published in the journal of The London and Middlesex Archaeology Society (LAMAS). We would also like to thank an anonymous reviewer for their helpful comments.

\section{Competing Interests}

The authors have no competing interests to declare.

\section{Author Contribution}

EVJ and HFM did the zooarchaeological analysis. EVJ drew the figures and wrote the article with contributions from HFM and IH.

\section{References}

Archaeology South-East 2019 Post-excavation assessment and updated project design report: Archaeological excavations at 1-5 Benjamin Street, Farringdon, London Borough of Islington. ASE report no: 2018146. Brighton: ASE.

Betts, I 2002 Medieval 'Westminster' floor tiles. MoLAS monograph 11. London: Museum of London Archaeology Service.

Evans, D 2010 A good riddance of bad rubbish? Scatological musings on rubbish disposal and the handling of 'filth' in medieval and early post-medieval towns. In: De Groote, K, Tys, D and Pietersn, M (eds) Exchanging Medieval Material Cul- ture: Studies on archaeology and history presented to Frans Verhaeghe. Brussels: Flemish Heritage Institute. pp. 267-278.

Greig, J 1981 The investigation of a medieval barrel-latrine from Worcester. Journal of Archaeological Science, 8(3): 265-282. DOI: https://doi.org/10.1016/03054403(81)90003-0

Hammer, Ø, Harper, D A T and Ryan, P D 2001 PAST: Paleontological statistics software package for education and data analysis. Palaeontologia Electronica, 4(1): 9.

Hogg, I et al. In prep. Excavations at 1-5 Benjamin Street, Farringdon; activity and tile making at the Hospitaller Priory of St John of Jerusalem.

Johnson, E 1985 Current developments in bone technology. Advances in Archaeological Method and Theory, 8: 157-235. DOI: https://doi.org/10.1016/B978-012-003108-5.50010-5

Johnson, E V, Parmenter, P C R and Outram, A K 2016 A new approach to profiling taphonomic history through bone fracture analysis, with an example application to the Linearbandkeramik site of Ludwinowo 7. Journal of Archaeological Science: Reports, 9: 623-629. DOI: https://doi.org/10.1016/j.jasrep.2016.08.047

Outram, A K 2001 A new approach to identifying bone marrow and grease exploitation: why the "indeterminate" fragments should not be ignored. Journal of Archaeological Science, 28: 401-410. DOI: https://doi.org/10.1006/ jasc.2000.0619

Rielly, K 2006 The animal bone. In: Seeley, D, Phillpotts, C and Samuel, M (eds.) Winchester Palace: Excavations at the Southwark Residence of the Bishops of Winchester. Museum of London Archaeology Service Monograph 31. London: Museum of London Archaeology Service. pp. 130-141.

Serjeantson, D 1996 The Animal Bones. In: Needham, S and Spense, T (eds.), Runnymede Bridge Research Excavations, Volume 2: Refuse and Disposal at Area 
16 East, Runnymede. London: British Museum. pp. 194-233.

Smith, D N 2013 Defining an indicator package to allow identification of 'cesspits' in the archaeological record. Journal of Archaeological Science, 40(1): 526-543. DOI: https://doi.org/10.1016/j. jas.2012.06.014

How to cite this article: Johnson, E V, Forsyth-Magee, H and Hogg, I 2019 Analysing Deposition and Site Formation Processes in Medieval Cess Pits Using Bone Fragmentation. Archaeology International, 22(1), pp. 72-78. DOI: https://doi.org/10.5334/ai-402

Submitted: 03 July 2019 Accepted: 30 September 2019 Published: 17 January 2020

Copyright: ( 2019 The Author(s). This is an open-access article distributed under the terms of the Creative Commons Attribution 4.0 International License (CC-BY 4.0), which permits unrestricted use, distribution, and reproduction in any medium, provided the original author and source are credited. See http://creativecommons.org/licenses/by/4.0/.

]u[ Archaeology International is a peer-reviewed open access journal published by Ubiquity Press. 